13 Singh BN, Nademanee K, Symoens J, Janssens M. Ketanserin and QTc prolongation. Eur Heart $\mathcal{F}$ 1987;8:667-8.

14 Medical Research Council Working Party on Mild to Moderate Hypertension. Ventricular extrasystoles during thiazide treatment: substudy of MRC mild hypertension trial. Br Med f 1983:287:1249-53.

15 Ragnarsson J, Hardarson T, Snorrason SP. Ventricular dysrhythmias in middle-aged hypertensive men treated either with a diuretic agent or a B-blocker. Actu Med Scand 1987;221:143-8.

16 Cohen JD, Neaton JD, Prineas RJ, Daniels KA. Diuretics, serum potassium and ventricular arrhythmias in the multiple risk factor intervention trial. and ventricular arrhythmias in

17 Medical Research Council Working Party. MRC trial of treatment of mild hypertension: principal results. Br Med J 1985;291:97-104.
18 Amery A, Birkenhaeger W, Brixko P, et al. Mortality and morbidity results from the European working party on high blood pressure in the elderly trial. Lancet 1985; i: 1359-64.

19 Wikstrand J, Warnold I, Olsson G, Tuomilehto J, Elmfeldt D, Berglund G, on behalf of the advisory committee. Primary prevention with metoprolol in patients with hypertension. Mortality results from the MAPHY Study. ҰAMA 1988:259:1976-82.

20 McKibbin JK, Pocock WA, Barlow JB, et al. Sotalol, hypokalaemia, syncope, and torsade de pointes. British Heart $\mathcal{f} 1984 ; 51: 157-62$.

21 Lewi PJ. Graphical assessment of statistical significance and clinical-biological relevance. Drug Development Research (in press).

(Accepted 16 November 1988)

\section{Comparison of starting antiemetic treatment 24 hours before or concurrently with cytotoxic chemotherapy}

\author{
C J Williams, C Davies, M Raval, J Middleton, \\ J Luken, B Stone
}

\section{CRC Medical Oncology \\ Unit, Southampton \\ General Hospital, \\ Southampton SO9 4XY \\ C J Williams, DM, senior \\ lecturer \\ C Davies, medical student \\ M Raval, medical student \\ J Middleton, SRN, \\ chemotherapy sister \\ J Luken, SRN, chemotherapy \\ sister}

B Stone, data coordinator

Correspondence to:

Dr Williams.

BrMed f 1989;298:430-1 parison of two different schedules.
Two of the main side effects of cytotoxic chemotherapy are nausea and vomiting, which may be severe enough to cause some patients to abandon effective treatment. Although antiemetics can ameliorate the degree of nausea and vomiting, none is universally effective, and emesis is often rated by patients as their most distressing side effect.' ${ }^{\prime}$ Recent trials have used combinations of antiemetics whose mechanism of action is likely to be different. Both domperidone (a dopamine antagonist) and dexamethasone (mechanism unknown) have useful antiemetic activity. They and other drugs have been used in various schedules, starting the night before, hours before, or concurrently with chemotherapy. We made a randomised com-

\section{Patients, methods, and results}

Patients receiving chemotherapy as outpatients were selected for inclusion; the nature of the trial was explained, and all gave oral consent. Patients were receiving combination chemotherapy with a regimen of either: moderate emetic potential (cyclophosphamide, doxorubicin, vincristine, and prednisolone; or procarbazine, etoposide, prednisolone, and doxorubicin; or vincristine, doxorubicin, and prednisolone); or mild emetic potential (chlorambucil, vinblastine, procarbazine, and prednisolone; or cyclophosphamide and etoposide). Patients were classified according to the emetogenic potential of the chemotherapy and whether they had $(n=20)$ or had not $(n=20)$ received prior chemotherapy. All prior chemotherapy had been of low emetic potential (often oral alkylating agents).

All patients began treatment 24 hours before starting chemotherapy. Those randomised to active treatment received oral domperidone $20 \mathrm{mg}$ and dexamethasone $4 \mathrm{mg}$, both six hourly, for 24 hours before chemotherapy. Patients randomised to the control group received matched placebos in the same schedule. When the cytotoxic chemotherapy was given both groups took oral domperidone $20 \mathrm{mg}$ and dexamethasone $4 \mathrm{mg}$ six hourly for 24 hours.

Potential side effects were assessed on a linear analogue scale. The scale was explained to patients, who completed it 24 hours after starting cytotoxic chemotherapy and returned it to the researchers. Patients rated their nausea, vomiting, and 18 other potential side effects of chemotherapy or the antiemetics on a $100 \mathrm{~mm}$ line. Results were analysed with the Mann-Whitney $U$ test $^{2}$ as the unpaired data did not conform to a normal distribution. Confidence intervals were calculated with the method of Campbell and Gardner. ${ }^{3}$ Low scores on the assessment scales indicated little toxicity and high scores severe side effects.

The table shows the ranked scores for nausea in the two groups, the difference being significant $(p=0 \cdot 001)$. As highly emetogenic cytotoxic drugs, such as cisplatin, were not used a high proportion of patients $(40 \%)$ reported no vomiting. Despite this most patients with severe vomiting were in the placebo group. Median scores were 1 for the active group and 14.5 for the placebo group. The estimated difference was $9.99(95 \%$ confidence interval 0 to $14 \cdot 9 ; p=0 \cdot 02)$.

Ranked scores on linear analogue self assessment scale for nausea in patients randomised to active antiemetic treatment $(n=20)$ or placebo $(n=20)^{\star}$

\begin{tabular}{ccc|clc}
\hline Score & Treatment & Rank & Score & Treatment & Rank \\
\hline 0 & Active & $3 \cdot 5$ & 22 & Active & 21 \\
0 & Active & $3 \cdot 5$ & 25 & Active & 22 \\
0 & Active & $3 \cdot 5$ & 30 & Placebo & $23 \cdot 5$ \\
0 & Placebo & $3 \cdot 5$ & 30 & Active & $23 \cdot 5$ \\
0 & Active & $3 \cdot 5$ & 35 & Placebo & 25 \\
0 & Active & $3 \cdot 5$ & 38 & Placebo & 26 \\
2 & Active & 7 & 42 & Placebo & 27 \\
7 & Active & 8 & 45 & Placebo & 28 \\
8 & Active & 9 & 50 & Placebo & $29 \cdot 5$ \\
10 & Placebo & $10 \cdot 5$ & 50 & Placebo & $29 \cdot 5$ \\
10 & Active & $10 \cdot 5$ & 52 & Active & 31 \\
12 & Placebo & 12 & 60 & Placebo & 32 \\
13 & Active & 13 & 64 & Placebo & 33 \\
15 & Placebo & 15 & 68 & Placebo & 34 \\
15 & Active & 15 & 71 & Placebo & 35 \\
15 & Placebo & 15 & 74 & Placebo & 36 \\
18 & Active & 17 & 76 & Active & 37 \\
20 & Active & $18 \cdot 5$ & 82 & Placebo & 38 \\
20 & Active & $18 \cdot 5$ & 86 & Placebo & 39 \\
21 & Active & 20 & 95 & Placebo & 40 \\
\hline
\end{tabular}

Active range $0-76$, median score 14 , sum of ranks $(A)=288 \cdot 5$; placebo range $0-95$, median score 50 , sum of ranks $(P)=531 \cdot 5$.

Estimate of difference between $A$ and $P=31 \cdot 50 ; 95 \%$ confidence interval for difference 14.9 to $49 \cdot 0 ;$ Mann-Whitney U test $\mathrm{p}=0.001$.

*Other variables measured were vomiting, drowsiness, concentration, perception of time, perception of distance, feelings of dissociation, coordination, dizziness, dry mouth, heartburn, diarrhoea, constipation, palpitations, thirst, polyuria, restlessness, blurred vision, tremor, mood, and appetite.

The differences between the groups for the 18 other variables measured were not significant, though moderately large increases in scores were seen for thirst, dry mouth, and restlessness in the placebo group, which may have resulted from the effects of increased emesis.

\section{Comment}

Our trial shows that a 24 hour pretreatment with domperidone and dexamethasone significantly reduced nausea and vomiting in patients receiving mild to moderate emetogenic chemotherapy. This could be explained by the pharmacokinetics of the antiemetics used. Domperidone has a half life of about $7 \cdot 5$ hours and dexamethasone of three to four hours. As the drugs were given six hourly for the 24 hours before chemotherapy accumulation would have taken place. ${ }^{+}$Steady state concentrations would have been approached in the six hours after administration of the 
cytotoxic drugs, just when the risk of emesis is highest. ${ }^{5}$ Conversely, in the placebo group antiemetic drug concentrations would have been lower during the period of maximum risk of emesis and approaching a steady state only the next day. Other drugs likely to accumulate during pretreatment may also be suitable, and their pharmacokinetics should be studied.

We thank Janssen Pharmaceutical Limited, who generously supplied the domperidone and dexamethasone with matched placebo.
I Coates $\mathrm{R}$, Abraham S, Kaye SB, et al. On the receiving end-patient perception of the side effects of cancer chemotherapy. Eur 7 Cancer Clin Oncol 1983;19:203-8

2 Mann HB, Whitney DR. On a test whether one or two random variables is stochastically larger than the other. Annals of Mathematical Statistics 1947;18:

3 Campbell MJ, Gardner MJ. Calculating confidence intervals for some non-parametric analyses. Br Med I 1988;296:1454-6.

4 Katzung BG, ed. Basic and clinical pharmacology. 3rd ed. Norwalk, Connecticut: Appleton and Lange, 1986:23-43.

5 Laszlo J, Lucas VS. Emesis as a critical problem in chemotherapy. $N$ Engl $\mathcal{f}$ Med 1981;305:948-52.

(Accepted 17 November 1988)

\section{Lack of effect of acyclovir on postherpetic neuralgia}

\author{
M W McKendrick, J I McGill, M J Wood
}

In 1986 we reported that in 209 elderly immunocompetent patients with herpes zoster oral acyclovir ( $800 \mathrm{mg}$ five times daily for seven days) significantly accelerated the rate of resolution of the rash and reduced the acute pain.' The reduction in pain did not, however, seem to continue for more than a few days after the treatment was stopped. Altogether 376 patients were ultimately enrolled in that trial, and we report here the effect of acyclovir on postherpetic neuralgia.

\section{Patients, methods, and results}

This randomised, double blind, placebo controlled domiciliary based study was conducted in Sheffield, Birmingham, and Southampton. All 376 patients were aged 60 or over and were entered into the trial within 72 hours after the onset of the rash. They were given placebo or oral acyclovir $800 \mathrm{mg}$ five times daily for seven days. Patients were seen 28 days after entry and at monthly intervals thereafter until six months or they were pain free, whichever occurred sooner. At each visit the patient was asked about pain in the previous four weeks. The severity of pain was recorded on a visual analogue scale of $0-100$ ranging from "none" to "very severe." For the purposes of analysis this was converted to nil $=0,1-24=1,25-75=2$, and $76-100=3$.

Data on 364 patients (181 taking acyclovir and 183 taking placebo) were suitable for analysis (177 from Sheffield, 113 from Birmingham, 74 from Southampton). The groups were comparable for demographic variables.

There was no evidence of any effect of acyclovir on the incidence or severity of postherpetic neuralgia during the six months of follow up (table). Further analysis of the data according to severity of pain at onset, the interval between the onset of the rash and the start of treatment ( $<48$ hours or $48-72$ hours), and age $(60-69$ and $\geqslant 70)$ failed to identify any subgroup in which acyclovir had an effect. In the placebo group the incidence and severity of postherpetic neuralgia decreased steadily during follow up. One month after the onset of the rash 110 out of $180(61 \%)$ patients still had some pain, but this proportion had fallen to 38 out of $156(24 \%)$ by three months and to 20 out of 155 $(13 \%)$ at six months.

\section{Comment}

In the first 209 patients studied oral acyclovir given as treatment for herpes zoster significantly reduced pain and analysis of the data on the total population recruited confirmed these findings. ${ }^{2}$ There was, however, no evidence of a reduction in the incidence or severity of postherpetic neuralgia. This was not altogether unexpected as analysis of data from the acute phase did not show any difference in mean pain scores of patients taking acyclovir and placebo beyond 21 days, ${ }^{1}$ and five days of treatment with intravenous acyclovir did not affect the incidence of postherpetic neuralgia. Would a longer duration of antiviral treatment have a more protracted effect on the pain? An American study of oral acyclovir in acute herpes zoster showed that a 10 day course at a daily dose similar to the one we used significantly reduced postherpetic neuralgia, particularly the chronic type of pain. Further studies of longer courses of acyclovir are needed.

In this study the incidence of postherpetic neuralgia in the placebo group was surprisingly low $(13 \%$ at six months), given that only people aged 60 or over were enrolled into the trial. The risk of this complication rises greatly with increasing age, and reports have quoted rates as high as $30-40 \%$ for patients over $60 .^{4}$ Our study was, probably, the largest prospective study of elderly patients with herpes zoster, and we believe that it more accurately reflects the true incidence of postherpetic neuralgia.

1 McKendrick MW, McGill JI, White JE, Wood MJ. Oral acyclovir in acute herpes zoster. Br.Med J 1986;293:1529-32.

Wood MJ, Ogan PH, McKendrick MW, Care CD, McGill JI, Webb EM. Efficacy of oral acyclovir treatment of acute herpes zoster. Am $7 \mathrm{Med}$ $1988 ; 85: 79-83$.

3 Huff JC. Oral acyclovir therapy of acute herpes zoster: a multi-centre study. Research and Clinical Forums 1987;9:37-45.

4 De Moragas JM, Kierland RR. The outcome of patients with herpes zoster. Arch Dermatol 1957;75:193-6.

5 Ragozzino MW, Melton LJ III, Kurland LT, Chu CP, Perry HO. Population based study of herpes zoster and its sequelac. Medicine (Baltimore) 1982;61 $310-6$

(Accepled 22 November 1988

Distribution of pain scores over six months for patients with postherpetic neuralgia treated with acyclovir or placebo. Figures are numbers (percentages) of patient.

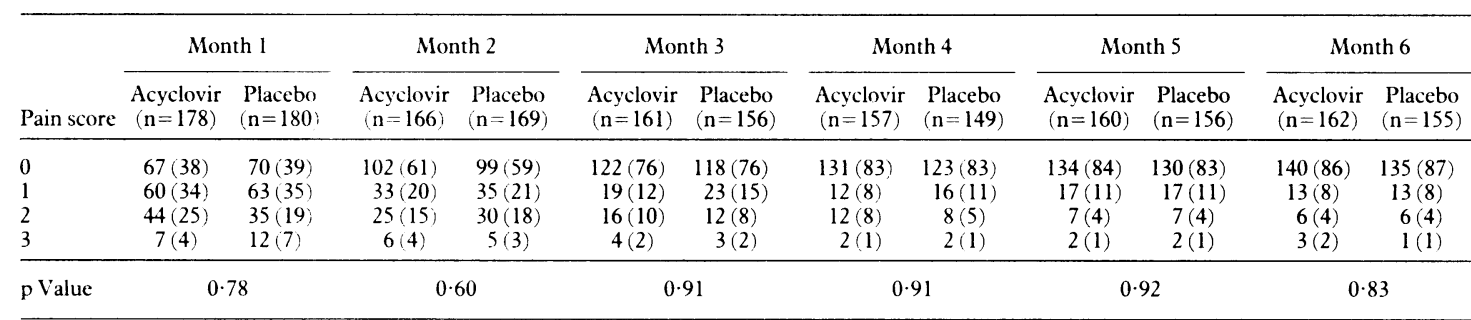

